\title{
ERRATUM
}

Pierre Samozino • Nicolas Horvais · Frédérique Hintzy

\section{Interactions between cadence and power output effects on mechanical efficiency during sub maximal cycling exercises}

Published online: 6 April 2006

(C) Springer-Verlag 2006

Eur J Appl Physiol (2006) DOl: 10.1007/s00421-0060132-x

The first and last names of the authors were reversed in the original article to which this erratum refers.

The online version of the original article can be found at http:// dx.doi.org/10.1007/s00421-006-0132-x

P. Samozino $(\bowtie) \cdot$ N. Horvais · F. Hintzy

Laboratoire de Modélisation des Activités Sportives,

Université de Savoie-CISM, 73-376 Bourget du lac, France

E-mail: pierre.samozino@univ-savoie.fr 